\title{
A case of endobronchial lipoma mimicking bronchial asthma
}

This article was published in the following Dove Press journal:

International Medical Case Reports Journal

18 May 2009

Number of times this article has been viewed

\author{
Sevket Ozkaya' \\ Hasan Demir' \\ Serhat Findik ${ }^{2}$ \\ 'Samsun Chest Diseases and Thoracic \\ Surgery Hospital, Samsun, Turkey; \\ ${ }^{2}$ Department of Pulmonary Medicine, \\ Faculty of Medicine, Ondokuz Mayis \\ University, Kurupelit, Samsun, Turkey
}

\begin{abstract}
Endobronchial lipoma is a rare neoplasm of the tracheobronchial tree and it may cause irreversible pulmonary damage due to recurrent pneumonia. Rarely, it may mimic bronchial asthma. We present a 53-year-old woman with an endobronchial lipoma, which had been treated as a bronchial asthma for four years. She also had developed recurrent pneumonia three times.
\end{abstract}

Keywords: endobronchial lipoma, asthma, radiology, bronchoscopy

\section{Introduction}

Pulmonary lipomas originate most commonly in the trachea or bronchi and they have been estimated to compose about $0.1 \%$ of all pulmonary tumors. ${ }^{1}$ Endobronchial lipomas may cause clinically significant problems including recurrent pneumonia and irreversible pulmonary damage..$^{2-4}$ Bronchial asthma-like symptoms due to endobronchial lipoma is extremely rare and only a few cases have been reported. ${ }^{2,5}$ We present a case of endobronchial lipoma, which had been treated as bronchial asthma for four years.

\section{Case report}

A 53-year-old woman was admitted to our hospital with the complaints of cough, sputum, wheezing, and dyspnea for four years and has been treated as bronchial asthma. She also had developed recurrent pneumonia three times. Physical examination revealed decrement of breath sounds on her lower right zone. Spirometric pulmonary function tests resulted as follows: forced expiratory volume in one second $\left(\mathrm{FEV}_{1}\right), 64 \%$; forced vital capacity (FVC), 57\%; $\mathrm{FEV}_{1} / \mathrm{FVC}, 92.3 \%$; not reversible with bronchodilators (Figure 1). A chest X-ray on admission demonstrated a linear atelectasis on the right lower zone with elevation of the right hemidiaphragm. Since neither the patients' historical features with physical examination findings nor spirometric results with radiologic features were consistent with bronchial asthma we thought that bronchial asthma diagnosis was not true. We performed computed tomographic (CT) scans of thorax which showed an endobronchial lesion within intermediate bronchus (Figure 2) and fiberoptic bronchoscopy that revealed a wellcircumscribed polypoid endobronchial lesion that almost completely obstructed the lumen of the intermediate bronchus (Figure 3). Since histopathologic examinations of the biopsy specimens were not sufficient for final diagnosis, the patient underwent a right thoracotomy and bronchiotomy. Histopathologic examination of the surgical specimen was reported as lipoma. The postoperative course was uneventful and the
Correspondence: Serhat Findik Department of Pulmonary Medicine, Faculty of Medicine, Ondokuz Mayis University, Kurupelit, Samsun, Turkey Tel +905325868869

Email serhatfindikl@yahoo.com 


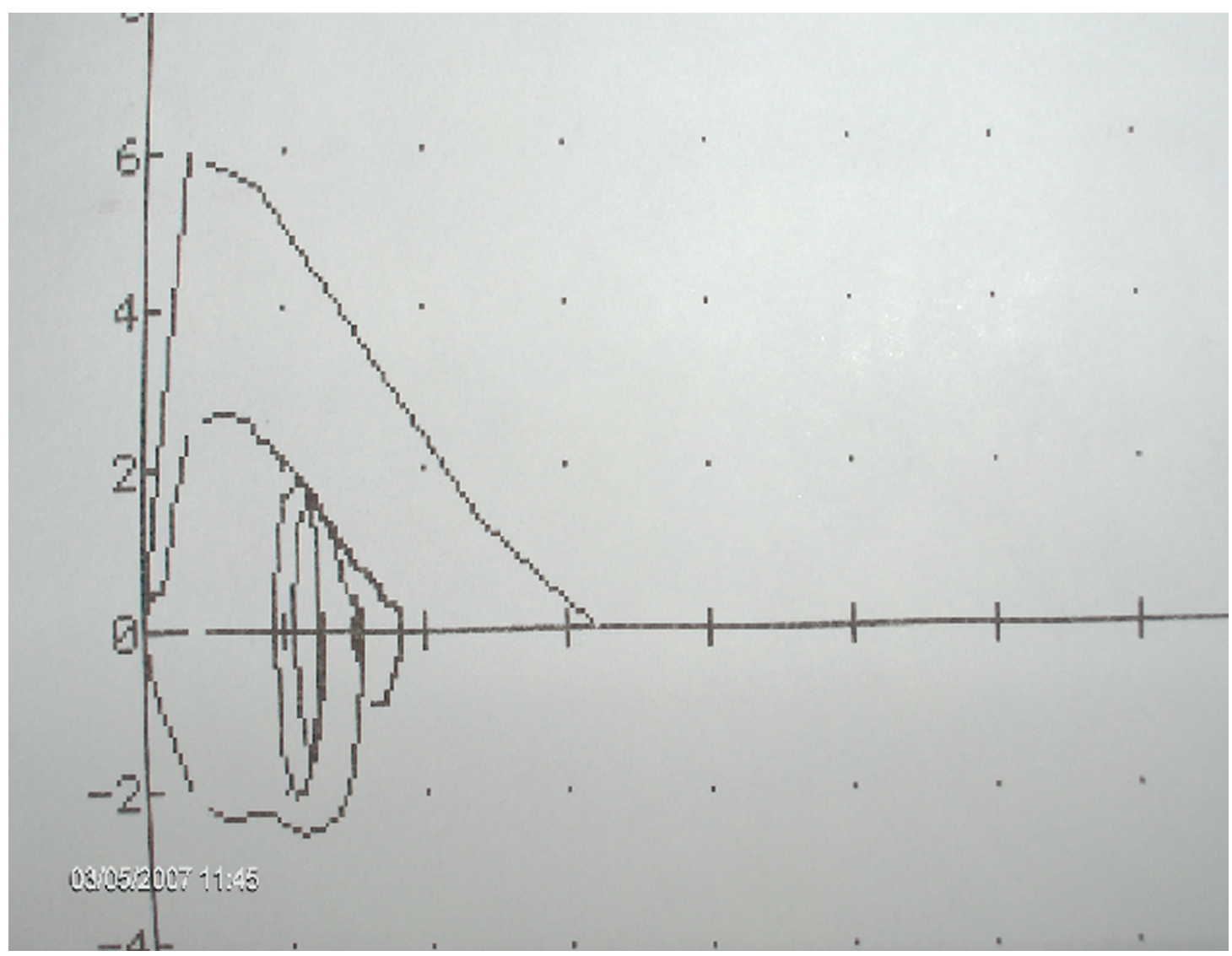

Figure I Spirometric pulmonary function curves.

patient was discharged on the 5th hospital day. She was asymptomatic at the sixth month of follow-up.

\section{Discussion}

Benign tumors of tracheobronchial tree are rare entities and lipomas are among the rarest benign tumors. Endobronchial lipomas consist of mature adipose tissue and some fibrous components lined with normal bronchial epithelium. Therefore, small biopsies taken by fiberoptic bronchoscopy may not be diagnostic, ${ }^{3,6}$ as in our case.

The clinical problems of endobronchial lipomas are fundamentally caused by obstruction of airflow including recurrent pneumonia, bronchiectasis, and irreversible pulmonary damage. Bronchial asthma-like symptoms are extremely rare and only a few cases have been reported. ${ }^{2,5}$

In the literature, Muroaka and colleagues reviewed 64 patients with endobronchial lipomas. Fifty patients (78\%) were male with a mean age of 60 years. Lipomas were located within the right bronchial tree in 40 patients $(62.5 \%)$. Forty-eight patients (75\%) were symptomatic, including cough, sputum, hemoptysis, fever, and dyspnea. About $80 \%$ of the patients had abnormal radiographic findings, which were atelectasis, consolidation, mass shadows, and pleural effusion. $^{7}$

Our patient was female and she suffered from cough, sputum, wheezing, and dyspnea. She had been treated for bronchial asthma and had developed recurrent pneumonia three times.

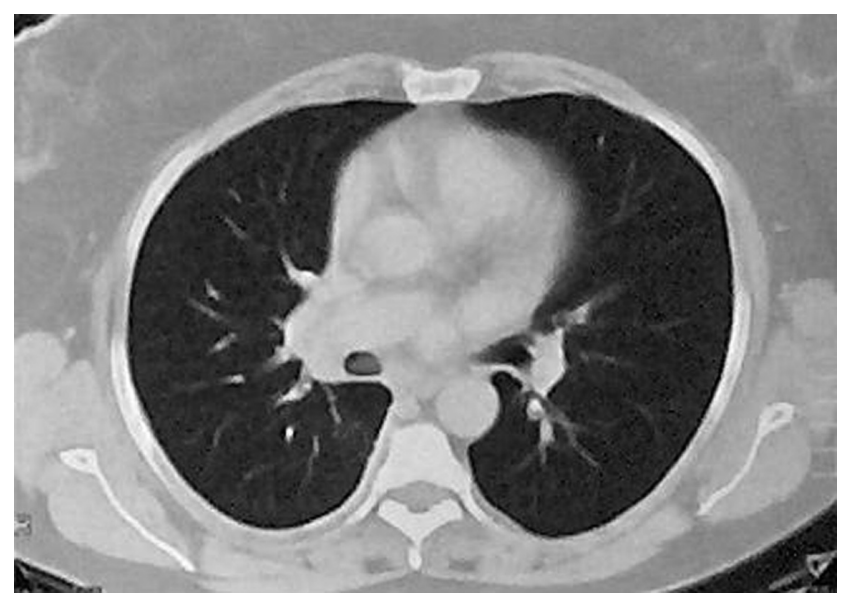

Figure 2 Computed tomographic scans of thorax showed an endobronchial lesion within intermediate bronchus. 


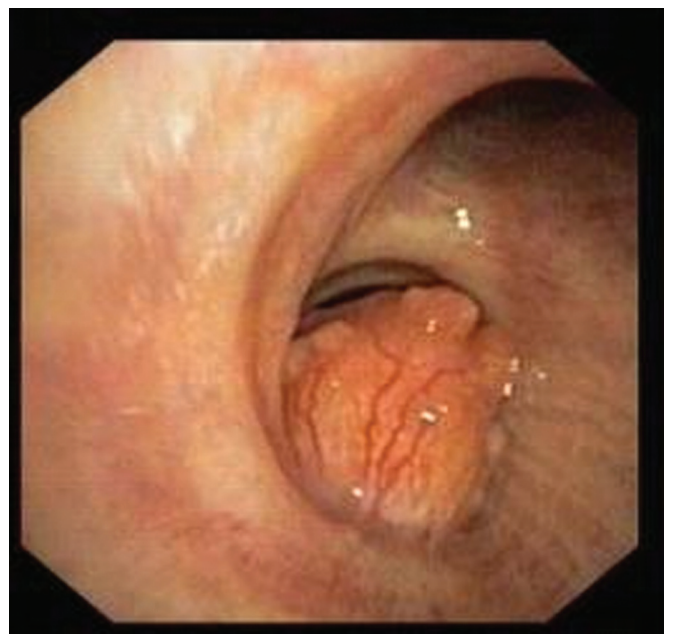

Figure 3 Fiberoptic bronchoscopy revealed a well-circumscribed polypoid endobronchial lesion that almost completely obstructed the lumen of the intermediate bronchus.

Computed tomography and magnetic resonance imaging (MRI) are reported to be helpful in establishing the diagnosis by demonstrating a fatty tumor within the bronchial lumen. CT is highly specific and sensitive for the detection of fat, and the presence of fat within a lesion suggests a benign etiology, such as lipoma or hamartoma. ${ }^{8,9}$ Several reports of MRI appearance of lipoma have shown high signal intensity on T1-weighted images and intermediate signal density on proton density and T2-weighted images, compatible with normal fat. ${ }^{10}$ Although fiberoptic bronchoscopy is the most valuable method of diagnosis of endobronchial lesions, it is not usually sufficient to make diagnosis of endobronchial lipomas, as in our case. Thus, surgical or bronchoscopic resection must be performed in order to reach final diagnosis. Although endobronchial removal with laser therapy is the preferred treatment option, ${ }^{9}$ the patient underwent right thoracotomy and bronchiotomy since we had technical dificulties related to interventional bronchoscopy.

Bronchial asthma-like picture may also be seen in (1) upper airway obstructions including both extrathoracic (eg, vocal cord dysfunction syndrome, epiglottidis) and intrathoracic causes (eg, tracheal stenosis, endobronchial tumors, right-sided aortic arch), and (2) lower airway obstructions such as aspiration, chronic obstructive pulmonary disease, or bronchiectasis. Thus, the diagnosis of conditions other than bronchial asthma should be considered when the initial evaluation suggests their presence or when the patients do not respond to conventional asthma medications, ${ }^{11}$ as in our case. Physical examinatin findings, spirometric results, and radiologic features are helpful for the exact diagnosis.

In conclusion, although endobronchial lipomas occur rarely, it must be kept in mind in differential diagnosis of bronchial asthma and also in patients with a history of recurrent pneumonia.

\section{Disclosure}

The authors report no conflicts of interest in this work.

\section{References}

1. Schraufnagel DE, Morin JE, Wang SE. Endobronchial lipoma. Chest. 1979;75:97-99.

2. Aleva RM, Wouters B, Kraan J, Postmus PE. Late onset asthma? Eur Respir J. 1991;4:239-241.

3. Huisman C, von Kralingen KW, Postmus PE, Sutedja TG. Endobronchial lipoma: A series of three cases and the role of electrocautery. Respiration. 2000;67:689-692.

4. Rao PSR, Wallis J. Endobronchial lipoma. Eur J Cardiothorac Surg 2001;19:512.

5. Basoglu A, Celik B, Akdag AO, Sengul AT. Endobronchial lipoma: A rare cause of bronchial occlusion. Interact Cardiovasc Thorac Surg. 2004;3:263-264.

6. Fujino S, Matsuda T, Asada Y, Konishi T, Kato H, Mori A. Benign endobronchial lipoma: A case report and review of literature. J Bronchol. 1996;3:199-202.

7. Muraoka M, Oka T, Akamine S, et al. Endobronchial lipoma: Review of 64 cases reported in Japan. Chest. 2003;123:293-296.

8. Mendelsohn SL, Fagelman D, Zwanger-Mendelsohn S. Endobronchial lipoma demonstrated by CT. Radiology. 1983;148:790.

9. Ko JM, Jung JI, Park SH, et al. Benign tumors of the trachebronchial tree: CT-pathologic correlation. AJR Am J Roentgenol. 2006;186: 1304-1313.

10. Rodriguez E, Pombo F, Gallego C, Otero I. Endobronchial lipoma: computed tomography and magnetic resonance. Chest. 1994; 105:1628.

11. Smyrnios NA, Irwin RS. Wheeze. In: Irwin RS, Curley FJ, Grossman RF, editors. Diagnosis and treatment of symptoms of the respiratory tract. Armank, NY: Futura Publishing Company; 1997. p. 117-153.

\section{Publish your work in this journal}

The International Medical Case Reports Journal is an international, peer-reviewed open-access journal publishing original case reports from all medical specialties. Previously unpublished medical posters are also accepted relating to any area of clinical or preclinical science. Submissions should not normally exceed 2,000 words or

\section{Dovepress}

4 published pages including figures, diagrams and references. The manuscript management system is completely online and includes a very quick and fair peer-review system, which is all easy to use. Visit http://www.dovepress.com/testimonials.php to read real quotes from published authors. 